\title{
Research Paper: Comparing the Effectiveness of the Triple P-Positive Parenting Program and Parenting Program of Acceptance and Commitment Therapy on Parent-Child Relationship and Self-efficacy of Moth- ers With Oppositional Defiant Disorder Children
}

\author{
Shahriar Amini Naghani ${ }^{1}$ (D, Samaneh Najarpourian ${ }^{2 *}$ (D), Seyed Abdolvahhab Samavi² ${ }^{2}$
}

1. Department of Counseling and Psychology, University of Hormozgan, Bandar Abbas, Iran

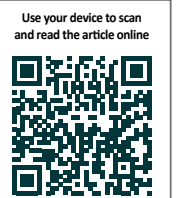

Citation Amini Naghani Sh, Najarpourian S, Samavi SAV. Comparing the Effectiveness of the Triple P-Positive Parenting Program and Parenting Program of Acceptance and Commitment Therapy on Parent-Child Relationship and Self-efficacy of Mothers With Oppositional Defiant Disorder Children. Journal of Research \& Health. 2020; 10(2):111-122. http://dx.doi.org/10.32598/JRH.10.2.7

doij http://dx.doi.org/10.32598/JRH.10.2.7

\section{(c) (1) (\$)}

Article info:

Received: 14 Sep 2019

Accepted: 05 Jan 2020

Publish: 01 Mar 2020

\section{Keywords:}

Positive psychology, Acceptance and Commitment, Oppositional defiant disorder, Parent-child relations, Self-efficacy

\begin{abstract}
Background: Parents may face challenges in establishing relationships with their children with Oppositional Defiant Disorder (ODD). This research was conducted to compare the effectiveness of the Triple P-Positive Parenting Program (Triple P) and the Acceptance and Commitment Therapy (ACT)-based parenting on the parent-child relationship and parental self-efficacy of parents with ODD children.
\end{abstract}

Methods: The design of this research was quasi-experimental and included two intervention groups and one control group. The study population consisted of all mothers of first-, second-, and third-grade primary school children with ODD who lived in Shahrekord City, Iran in 2018. The study mothers were chosen by purposive sampling method and then divided into three groups of Triple P, ACT, and control. Data were gathered using the Oppositional Defiant Disorder Rating Scale (ODDRS), the Parent-Child Relationship Scale (PCRS) and the Parental Self-Efficacy Questionnaire (PSEQ). Data analyses were carried out using multivariate analysis of variance, repeated measures analysis of variance and post hoc Bonferroni test in SPSS.

Results: Significant differences in the Post-test parent-child relationship $(\mathrm{F}=4.53, \mathrm{P}<0.05)$ and follow-up parent-child relationship $(\mathrm{F}=8.03, \mathrm{P}<0.05)$ and Post-test parental self-efficacy $(\mathrm{F}=11.24, \mathrm{P}<0.05)$ and follow-up parental self-efficacy $(\mathrm{F}=11.04, \mathrm{P}<0.05)$ were observed among Triple $\mathrm{P}, \mathrm{ACT}$, and control group. The findings also showed no significant difference in posttest and follow-up phases $(\mathrm{P}>0.05)$ between Triple $\mathrm{P}$ and ACT groups. There were significant differences in parent-child relationships and parental self-efficacy between Pre-test and Post-test phases in Triple $\mathrm{P}$ and ACT $(\mathrm{P}<0.05)$ groups, but there was no significant difference between the Post-test and follow-up stages $(\mathrm{P}>0.05)$.

Conclusion: The results of this research suggest that Triple P and ACT are effective techniques for improving parent-child relationships and parental self-efficacy in mothers of children with ODD.

\section{* Corresponding Author:}

Samaneh Najarpourian, $P h D$.

Address: Department of Psychology and Counseling, Faculty of Humanities, University of Hormozgan, Bandar Abbas, Iran.

Phone: +98 (17) 7314044

E-mail: s.najarpourian@yahoo.com 


\section{Introduction}

ne of the most prevalent clinical disorders in children and adolescents is the $\mathbf{0}$ Oppositional Defiant Disorder (ODD). It is characterized by restless mood and behavior, contradiction and disobedience, insolence, abusive behavior, irritation, loss of temper, non-observance of regulations and rules, and illegal behavior [1]. Various studies have revealed different incidence rates for this disorder across populations. In one recent study, the prevalence of the disorder among children aged 3-9 years was reported to range between $6 \%$ and $9 \%$, with the risk of developing this disease as $22 \%$ [2]. Studies indicate that ODD is more common in boys but has nearly the same prevalence in boys and girls after puberty [1].

ODD is a progressive and chronic disorder that, before pre-primary school, is hard to diagnose [3]. The prognosis of ODD is extremely unpredictable, and affected children are at risk of developing many other issues in adolescence and adulthood [4-6]. Etiologically, several factors for ODD have been suggested, ranging from genetic or biological factors to family, parenting, and social and environmental factors [7].

For the most aspect, children with ODD lack healthy family relationships, and studies have shown that inadequate parent-child relationships in these households are among the variables affecting the occurrence and severity of ODD $[4,8]$. The family's interaction with these children are based on unstable and punishing parenting, harsh and dry laws, low empathy, and the absence of beneficial relationships [9]. Parents often have poor parenting abilities. They are usually violent, aggressive, incapable and inconsistent in their disciplinary behavior, all point to the significance of parent-child relationship in ODD pathology [7]. Furthermore, these children do not talk to their parents and disobey and disagree with them [10], which indicates the importance of parentchild relationships in these families. Also, parents may feel that their disciplinary techniques are unsuitable and ineffective in parenting [11].

Belief in parental self-efficacy implies the parents' feeling and capacity to fulfill their responsibilities and parenting duties [12]. Parental self-efficacy also relates to the views or opinions of the parents about their ability to organize and execute several child parental responsibilities [13]. Based on Ardelt and Eccles' model, when parents believe in their low self-efficacy, they use punitive techniques. And, they are ready to leave persuasive tech- niques as they realize the challenge between themselves and their children's damaging behaviors. Eventually, the parents strongly believe that they lack a suitable parental self-efficacy level [14]. Believing in low self-efficacy of parents, however, can generate issues in parent-child relationships and cause inappropriate and maladaptive behaviors in children [12]. It appears that in ODD children, the severity and frequency of these behaviors are more than other children. It is therefore essential to provide these parents with suitable psychological interventions and parenting training [15].

The Triple P-Positive Parenting Program (Triple P) [16] is one of the ideal parenting programs that is efficient in solving parenting issues in families with ODD children. The program suggests altering the child's behavioral issues by correcting the family environment [17] and has three primary goals: 1. Improving and supporting parents' skills, understanding, trust and effectiveness; 2 . Fostering affection, safety, and entertainment, by reducing conflicts and violence; and 3. enhancing social welfare [18]. Triple P has five values: creating a healthy and appealing environment, providing an attractive teaching environment, setting a definitive discipline, having realistic expectations, and paying attention to one's role as a parent [19]. Research demonstrates that this program can be beneficial for parents ' and children's understanding, emotions, and behaviors [20-23].

Acceptance and Commitment Therapy (ACT) is another interventional protocol categorized as the third wave of conduct. This protocol has slowly entered the parenting field. The ACT is a cognitive-behavioral therapy that involves awareness, acceptance, and absence of knowledge as well as a precious and committed action to foster psychological flexibility [24]. ACT-based parenting improves the flexibility and capacity of parents to use parenting abilities in stressful circumstances by concentrating on the mental evaluation of their children's issues and their subjective significance of parenting $[25,26]$. By defining experiential avoidances and adequate reactions to these children's needs, ACT education has significant impacts on improving parents' conduct over children with developmental and cognitive disabilities [27-29]. In their research on the efficacy of ACT on parents of children with autism disorder, Gould et al. found that ACT could enhance beneficial parental behavior [30]

Because of these issues, there is no doubt that parents with ODD children have problems with children that, in turn, cause additional problems for the children and their parents. Therefore, to enhance the relationship between the parents and their children, it is essential to provide 
techniques for parenting education. Triple $\mathrm{P}$ is based on the behavioral first-wave conduct, and ACT-based parenting education is based on the behavioral third-wave studies, so they have shown excellent outcomes, and are more suitable techniques for educating these parents. The objective of this research was to compare the effectiveness of Triple P and ACT on parent-child relationship and self-efficacy of mothers with ODD children.

\section{Methods}

This study is a quasi-experimental research with a Pre-test-Post-test and follow-up (2-month) design with two intervention groups (Triple P and ACT) and one control group. The study population consisted of all mothers of the first-, second- and third-grade schoolchildren with ODD in Shahrekord City, Iran in 2018. Since it was not possible to accurately estimate the number of samples, we selected many samples in pilot projects. This sampling prevents accurate control of confounding variables; moreover, the size of each group can be at least 15 people in the experimental research [31]. Besides, the sample size of other studies is this number $[7,22,29]$. Therefore, according to the inclusion criteria, 45 patients were randomly chosen from the survey population and 15 patients were assigned to each group of Triple P group, ACT, control.

Inclusion criteria were diagnosis of ODD in children based on Oppositional Defiant Disorder Rating Scale (ODDRS) and diagnostic interview, 7 to 9 years old, mothers with at least high school diploma, absence of psychiatric disease pain, or using psychological interview-based neurological pills, and approval for therapy. Exclusion criteria were missing 1 intervention session, receiving other psychotherapy and support facilities during the sessions, and unwilling to continue the therapy sessions.

To observe the ethical principles, the researchers informed the subjects that the study has been designed to help and provide them with useful parental teachings. Their data would be kept confidential, and they could withdraw from the research whenever they wanted. Then, the women gave their verbal consent to take part in the study. There was no intervention for the control group. The Triple $\mathrm{P}$ group received group training in a total of eight 2-hour sessions based on the Sanders protocol [32], and the ACT group received group training based on the Coyne and Murrell protocol [33] and Hayes et al. textbook [24] in ten 90-minute weekly sessions. The summary of the training sessions is presented below.

\section{Summary of triple $P$ training sessions}

First session: familiarization with group members, the introduction of group regulations, significance of parenting, and a brief presentation of positive parenting, ODD, its symptoms and etiologies.

Second session: teaching the concepts and descriptions of positive parenting, dimensions and values of positive parenting (creating a secure atmosphere, establishing a positive teaching environment, applying the law of self-expression, having true expectations and taking care of yourself as a parent), causes of children's behavioral issues, including hereditary and family problems (casual reward for negativity).

Third session: strengthening beneficial relationships between parents and the child (promoting and strengthening good behavior, training in creating new abilities and behavior, various kinds of strengthening, physical affection, using good conduct table, informal education, and modeling), assignment.

Fourth session: teaching parents' skills to control the child's mild or severe unpleasant behaviors and learn how to deal with challenging behaviors (teaching how to provide instructions, codifying clear and unambiguous rules of dealing with violations of rules and regulations through a guided discussion, illustrating the calm and clear instruction, planned neglect, use of the method of ignoring mild problems (use of a logical consequence for severe adverse behaviors (use of silence method, use of dismissal method), common issues due to dismissal, giving assignment.

Fifth session: teaching how to control a child in situations where control is low, providing solutions for family survival (acting as a team, avoiding dispute, using the time of leisure and relaxation), recognizing troublemaker situations, training the measure steps planned for difficult situations, pre-preparation, entertaining activity selection, reward for proper behavior, use of consequence for negative and unfavorable behaviors, use of preventive discussion, giving assignment.

Sixth and seventh sessions: examining the issues of parents in how to interact with the child, discussing the issues of parents in applying directions, and creating techniques with the child in these two sessions. Eighth session: Reviewing previous subjects and ideas, obstacles to make the change (changes in the family, developmental stage of the child, and conditions of distress), 
offering strategies for holding change, exercising common issues and playing roles.

\section{Summary of ACT-based parenting sessions}

First session: familiarizing with group members, group rules, the features and indications of headstrong and disobedient children, the significance of parenting, and the differences between ACT parenting and other techniques;

Second session: learning creative helplessness using the metaphor of well, the metaphor of being caught in the sands, the metaphor of being caught in the swamp, giving the assignment;

Third session: Training the mind's productions, awareness of the mind's commands, and different types of families from the perspective of acceptance and commitment, giving the assignment;

Fourth session: learning the concept of controlling the problem rather than resolving it, using the metaphor of remembering the numbers 2,1 , and 3 , the metaphor of the ship with the monsters, and the hungry tiger metaphor and finally the assignment;

Fifth session: acceptance training and psychological flexibility and acceptance of negative thoughts and feelings instead of control, avoidance, and elimination using guest metaphor and assignment;

Sixth session: teaching self-observing and self-conceptualizing using chess metaphor and mindfulness exercises, practicing awareness of the finest sounds, practicing with the child, practicing the whole body examination, practicing eating raisins, and giving the assignment;

Seventh session: training mindfulness exercises, including practicing the awareness of the finest sounds, practicing with the child, practicing the whole body examination, practicing eating raisins, and giving the assignment;

Eighth session: teaching behavior change methods, teaching effective commanding, teaching prognoses, behaviors, contexts, behavioral consequences, teaching functional analysis of behavior, and giving the assignment;

Ninth session: learning values using the metaphor of the funeral, the metaphor of the gravestone, and the metaphor of the island, teaching the difference between values and goals and expectations, giving assignments;
Tenth session: reviewing previous discussions, summarizing, and summing up.

\section{Research instruments}

\section{Oppositional Defiant Disorder Rating Scale}

Hommersen [34] developed ODDRS based on the criteria for the Diagnostic and Statistical Manual of Mental Disorders (DSM), published by the American Psychiatric Association (APA) for the diagnosis of ODD in children aged 5-15 years. This scale has 8 items scored based on a 4-point Likert scale (from $0=$ Never to $3=$ Too high), with higher scores indicating higher severity of the disorder, and parents describe each child's symptoms based on their observations in the last 6 months. The developers reported a coefficient of reliability of 0.92 (Cronbach alpha) and a test-retest coefficient of reliability of 0.95 . Faramarzi et al. validated this scale and reported its coefficient of reliability as 0.93 calculated by the Cronbach alpha and 0.94 by the test-retest. Children's psychiatrists and clinical experts also confirmed their validity of content [35]. In our research, the Cronbach alpha coefficient of the scale was found as 0.70 .

\section{Parent-Child Relationship Scale}

Pianta developed the 30-item Parent-Child Relationship Scale (PCRS) that assess parents' perceptions of their relationship with their children. This scale consists of three subscales of conflict, proximity, and dependency, which collectively determine the parent-child relationship. The items are rated based on a 5-point Likert-type scale (from score 1 definitely is not applicable to score 5 is definitely applicable), and higher scores indicate better parent-child relationship [36]. Abarashi et al., while confirming the content validity of this scale, calculated its reliability with the Cronbach alpha coefficient. The reliability coefficients of conflict, proximity, dependency subscales and overall positive relationship were obtained $0.84,0.70,0.61$, and 0.86 , respectively [37]. In the present study, the Cronbach alpha coefficients of the proximity, dependence, and conflict subscales were 0.81 , 0.83 and 0.91 respectively, and the Cronbach alpha coefficient of the total scale was obtained 0.95 .

\section{Parental Self-efficacy Questionnaire (PSEQ)}

Dumka et al. developed the Parental Self-Efficacy Questionnaire (PSEQ) in 1996 to assess the overall level of parenting self-efficacy. This test examines parents' effectiveness and frustration when confronting the child's situations, also their ability to resolve parent-child 
conflicts and resilience in parenting. This instrument consists of 10 items that are scored based on a 7-point Likert-type scale from rarely to consistently, with higher scores indicating higher levels of parental self-efficacy. Dumka et al. reported the Cronbach alpha coefficient of this questionnaire as 0.70 [38]. In the study of Taleii et al., after confirming the content validity of the scale by 3 faculty members, the Cronbach alpha coefficient was reported as 0.70 [22]. In this study, its Cronbach alpha coefficient was calculated as 0.83 .

The descriptive indices mean and standard deviation and the inferential statistics Multivariate Analysis of Variance (MANOVA), repeated measures Analysis of Variance (ANOVA) and Bonferroni post hoc test were conducted in SPSS V. 22 for data analysis.

\section{Results}

With regard to descriptive data, most mothers had a diploma, so that $60 \%$ in the Triple P group, $60 \%$ in the ACT group and $53.3 \%$ in the control group had diploma education level, followed by BA and MA.
The Table 1 presents the mean and standard deviation values of the parent-child relationship and parental selfefficacy in Triple P, ACT, and control groups in three phases of Pre-test, Post-test, and follow-up. The findings indicate that the assumptions of MANOVA and repeated measures ANOVA have been established. MANOVA was used to compare the intervention and control groups.

The findings showed a substantial difference between the intervention groups and the control group $(\mathrm{P}<0.05)$ regarding the research variables at the post-test and follow-up phases, but not at the Pre-test phase (Table 2). The Bonferroni test (Table 3, 4 and 5) provided the pairwise comparison of Triple $\mathrm{P}$ and ACT in the Post-test and follow-up phase. Repeated measures ANOVA was used to compare the data at each stage of the research (pre-test, post-test, and follow-up).

The hypothesis of Mauchly's sphericity was created concerning the parent-child relationship variable, but no hypothesis of sphericity was developed for the self-efficacy variable; thus, the Greenhouse-Geisser correction row was used. The findings are as follows:

Table 1. Descriptive data on studied variables and analysis of variance by group

\begin{tabular}{|c|c|c|c|c|c|c|c|c|c|}
\hline \multirow{2}{*}{ Variable } & \multirow{2}{*}{ Test Stage } & \multicolumn{2}{|c|}{ Positive Parenting } & \multicolumn{2}{|c|}{$\begin{array}{l}\text { Commitment and } \\
\text { Acceptance }\end{array}$} & \multicolumn{2}{|c|}{ Control } & \multirow{2}{*}{$\mathbf{F}$} & \multirow{2}{*}{ Sig. } \\
\hline & & Mean & $\begin{array}{l}\text { Standard } \\
\text { Deviation }\end{array}$ & Mean & $\begin{array}{l}\text { Standard } \\
\text { Deviation }\end{array}$ & Mean & $\begin{array}{l}\text { Standard } \\
\text { Deviation }\end{array}$ & & \\
\hline \multirow{3}{*}{$\begin{array}{l}\text { Parent-Child } \\
\text { relationship }\end{array}$} & Pre-test & 46.73 & 99.14 & 93.71 & 82.14 & 06.75 & 006.15 & 16.0 & 0.849 \\
\hline & Post-test & 93.91 & 81.16 & 06.88 & 46.13 & 76 & 88.14 & 53.4 & 0.016 \\
\hline & Follow-up & 20.89 & 95.17 & 53.88 & 20.16 & 46.74 & 65.13 & 03.8 & 0.025 \\
\hline \multirow{3}{*}{ Self-efficacy } & Pre-test & 46.21 & 85.3 & 13.23 & 78.5 & 93.23 & 79.5 & 87.0 & 0.426 \\
\hline & Post-test & 33.38 & 64.10 & 60.37 & 01.8 & 26.25 & 16.6 & 24.11 & 0.001 \\
\hline & Follow-up & 06.36 & 66.8 & 46.39 & 95.11 & 46.24 & 82.5 & 04.11 & 0.001 \\
\hline
\end{tabular}

Table 2. Repeated measures ANOVA results on the parent-child relationship and parental self-efficacy

\begin{tabular}{cccccccc}
\hline Variables & $\begin{array}{c}\text { Source of } \\
\text { Variance }\end{array}$ & $\begin{array}{c}\text { Sum of } \\
\text { Squares }\end{array}$ & df & $\begin{array}{c}\text { Sum of } \\
\text { Squares }\end{array}$ & F & P & $\begin{array}{c}\text { Eta } \\
\text { Squared }\end{array}$ \\
\hline \multirow{2}{*}{$\begin{array}{c}\text { Parent-child } \\
\text { relationship }\end{array}$} & Time & 77.3806 & 2 & 38.1903 & 11.12 & 0.001 & 0.224 \\
& Time $\times$ group & 58.1871 & 4 & 89.467 & 97.2 & 0.024 & 0.124 \\
Self-efficacy & Time & 17.3431 & 72.1 & 88.1987 & 75.48 & 0.001 & 0.537 \\
\hline
\end{tabular}


Table 3. Bonferroni post hoc test results to compare Pre-test, Post-test, and follow-up for the parent-child relationship in each group

\begin{tabular}{|c|c|c|c|c|}
\hline Stage of Test & Groups & & Mean Difference & $\mathbf{P}$ \\
\hline \multirow{9}{*}{ Positive parenting } & \multirow{3}{*}{ Pre-test } & Post-test & -46.18 & 0.005 \\
\hline & & & & \\
\hline & & Follow-up & -73.15 & 0.045 \\
\hline & \multirow{3}{*}{ Post-test } & Pre-test & 46.18 & 0.005 \\
\hline & & & & \\
\hline & & Follow-up & 73.2 & 1 \\
\hline & \multirow{3}{*}{ Follow-up } & Pre-test & 73.15 & 0.045 \\
\hline & & & & \\
\hline & & Post-test & -73.2 & 1 \\
\hline \multirow{8}{*}{$\begin{array}{l}\text { Acceptance and } \\
\text { commitment }\end{array}$} & \multirow[b]{2}{*}{ Pre-test } & Post-test & -13.16 & 0.002 \\
\hline & & Follow-up & -60.16 & 0.011 \\
\hline & \multirow{3}{*}{ Post-test } & Pre-test & 13.16 & 0.002 \\
\hline & & & & \\
\hline & & Follow-up & -46.0 & 1 \\
\hline & \multirow{3}{*}{ Follow-up } & Pre-test & 60.16 & 0.011 \\
\hline & & & & \\
\hline & & Post-test & 46.0 & 1 \\
\hline \multirow{9}{*}{ Control } & \multirow{3}{*}{ Pre-test } & Post-test & -93.0 & 1 \\
\hline & & & & \\
\hline & & Follow-up & 60.0 & 1 \\
\hline & \multirow{3}{*}{ Post-test } & Pre-test & 93.0 & 1 \\
\hline & & & & \\
\hline & & Follow-up & 53.1 & 1 \\
\hline & \multirow{3}{*}{ Follow-up } & Pre-test & -60.0 & 1 \\
\hline & & & & \\
\hline & & Post-test & -53.1 & 1 \\
\hline
\end{tabular}

Regarding the time impact, the findings indicate a substantial difference between Pre-test, Post-test, and follow-up $(\mathrm{P}<0.05)$ in the parent-child relationship $(\mathrm{F}=$ 12.11) and parental self-efficacy $(\mathrm{F}=48.75)$. In both factors $(\mathrm{P}<0.05)$, the impact of the time in the group was important, showing a substantial difference between the research-based phases (Table 2). Bonferroni post hoc test was used to create pairwise comparisons of the Pretest, Post-test, and follow-up phases in each group. The findings are as follows:

Based on the outcomes for the parent-child partnership, there was a substantial difference between the Pre-test and Post-test and follow-up phases $(\mathrm{P}<0.05)$ in the Triple $\mathrm{P}$ and ACT groups, but there was no significant difference between them in the Post-test and follow-up phases $(\mathrm{P}>0.05)$. There was no significant difference between the various stages of the study in the control group $(\mathrm{P}>0.05)$ (Table 3$)$.
Based on the results for the parental self-efficacy variable, there was a significant difference in parental selfefficacy between the Pre-test, Post-test and follow-up stages in the Triple $\mathrm{P}$ and ACT groups $(\mathrm{P}<0.05)$, but there was no significant difference between the Post-test and follow-up stages $(\mathrm{P}>0.05)$. There was also no significant difference between the different phases of the experiment $(\mathrm{P}>0.05)$ in the control group (Table 4$)$.

Based on the results, there was a significant difference in the parent-child relationship and parental self-efficacy variables at the Post-test and follow-up between the Triple $\mathrm{P}$ and ACT groups and the control group $(\mathrm{P}<0.05)$. However, there was no significant difference between the Triple $\mathrm{P}$ and ACT groups ( $\mathrm{P}>0.05)$ (Table 5). 
Table 4. Bonferroni post hoc test results to compare Pre-test, Post-test, and follow-up for self-efficacy in each group

\begin{tabular}{|c|c|c|c|c|}
\hline Stage of Test & & & Mean Difference & $\mathbf{P}$ \\
\hline \multirow{9}{*}{ Positive parenting } & \multirow{3}{*}{ Pre-test } & Post-test & 16.86 & 0.001 \\
\hline & & & & \\
\hline & & Follow-up & -14.60 & 0.001 \\
\hline & \multirow{3}{*}{ Post-test } & Pre-test & 16.86 & 0.001 \\
\hline & & & & \\
\hline & & Follow-up & 2.26 & 0.768 \\
\hline & \multirow{3}{*}{ Follow-up } & Pre-test & 14.60 & 0.001 \\
\hline & & & & \\
\hline & & Post-test & -2.26 & 0.768 \\
\hline \multirow{8}{*}{$\begin{array}{l}\text { Acceptance and } \\
\text { commitment }\end{array}$} & \multirow{3}{*}{ Pre-test } & Post-test & -14.46 & 0.001 \\
\hline & & & & \\
\hline & & Follow-up & -16.33 & 0.002 \\
\hline & \multirow{2}{*}{ Post-test } & Pre-test & 14.46 & 0.001 \\
\hline & & Follow-up & -1.86 & 1 \\
\hline & \multirow{3}{*}{ Follow-up } & Pre-test & 16.33 & 0.002 \\
\hline & & & & \\
\hline & & Post-test & 1.86 & 1 \\
\hline \multirow{9}{*}{ Control } & \multirow{3}{*}{ Pre-test } & Post-test & -1.33 & 1 \\
\hline & & & & \\
\hline & & Follow-up & -0.53 & 1 \\
\hline & \multirow{3}{*}{ Post-test } & Pre-test & 1.33 & 1 \\
\hline & & & & \\
\hline & & Follow-up & 0.80 & 1 \\
\hline & \multirow{3}{*}{ Follow-up } & Pre-test & 0.53 & 1 \\
\hline & & & & \\
\hline & & Post-test & -0.80 & 1 \\
\hline
\end{tabular}

\section{Discussion}

The research findings showed that Triple $\mathrm{P}$ has a significant impact on improving the relationship between parent and child and the self-efficacy of the parents. The results also showed that the positive effect of Triple P remained until the follow-up stage. The findings for Triple $\mathrm{P}$ were consistent with some other research studies [2023]. Bodenmann et al. found that Triple $P$ could have a beneficial impact on maternal parenting and could also increase parental self-esteem and decrease parental stress and tension and enhance the relationship between mothers and children [39].

In a study on families with children who have attention deficit disorder, Momeni and Taziki found that Triple $P$ could have a beneficial impact on improving the relationship between mothers and children [23]. Talei et al. noted in another research that Triple P could have a beneficial effect on maternal self-efficacy improvement [22].

What is evident in this study and other studies is that Triple $\mathrm{P}$ can bring about beneficial adjustments in parents' cognitive beliefs, feelings, and conducts, taking into consideration the primary objectives of this protocol [18]. By enhancing the relationship between mothers and their children, Triple P can improve the expectations of parents and assist mothers to generate room where they fulfill the requirements of their children with ODD and do not perform destructive activities. These activities lead to a sense of parental self-efficacy. Parents of children with ODD often lack suitable parenting abilities and their disciplinary habits are often aggressive and inconsistent [7]. Triple P specifically examines parents' decisions and their interpretations of children's behaviors and adopts alternative methods to explain and 
Table 5. Bonferroni post hoc test results regarding the pairwise comparison of groups at Post-test and follow-up for the parent-child relationship and parental self-efficacy

\begin{tabular}{|c|c|c|c|c|c|c|}
\hline Variable & Stage of Test & & & Mean Difference & $\begin{array}{l}\text { Standard } \\
\text { Error }\end{array}$ & $\mathbf{P}$ \\
\hline \multirow{8}{*}{$\begin{array}{l}\text { Parent-child } \\
\text { relationship }\end{array}$} & & \multirow[t]{2}{*}{ Positive parenting } & $\begin{array}{l}\text { Acceptance and } \\
\text { commitment }\end{array}$ & 32.3 & 23.5 & 1 \\
\hline & Post-test & & Control & 50.16 & 23.5 & 0.009 \\
\hline & & \multirow{2}{*}{$\begin{array}{l}\text { Acceptance and } \\
\text { commitment }\end{array}$} & Positive parenting & -32.3 & 23.5 & 1 \\
\hline & & & Control & -18.13 & 25.5 & 0.048 \\
\hline & \multirow{4}{*}{ Follow-up } & \multirow[t]{2}{*}{ Positive parenting } & $\begin{array}{l}\text { Acceptance and } \\
\text { commitment }\end{array}$ & 216.0 & 70.5 & 1 \\
\hline & & & Control & 20.15 & 70.5 & 0.033 \\
\hline & & \multirow{2}{*}{$\begin{array}{l}\text { Acceptance and } \\
\text { commitment }\end{array}$} & Positive parenting & -216.0 & 70.5 & 1 \\
\hline & & & Control & 98.14 & 70.5 & 0.037 \\
\hline \multirow{8}{*}{$\begin{array}{c}\text { Parental } \\
\text { self-efficacy }\end{array}$} & & \multirow[t]{2}{*}{ Positive parenting } & $\begin{array}{l}\text { Acceptance and } \\
\text { commitment }\end{array}$ & 16.2 & 68.2 & 1 \\
\hline & Post-test & & Control & 18.15 & 71.2 & 0.001 \\
\hline & & \multirow{2}{*}{$\begin{array}{l}\text { Acceptance and } \\
\text { commitment }\end{array}$} & Positive parenting & -16.2 & 68.2 & 1 \\
\hline & & & Control & 02.13 & 66.2 & 0.001 \\
\hline & \multirow{4}{*}{ Follow-up } & \multirow[t]{2}{*}{ Positive parenting } & $\begin{array}{l}\text { Acceptance and } \\
\text { commitment }\end{array}$ & -99.2 & 38.3 & 1 \\
\hline & & & Control & 20.12 & 42.3 & 0.003 \\
\hline & & \multirow{2}{*}{$\begin{array}{l}\text { Acceptance and } \\
\text { commitment }\end{array}$} & Positive parenting & 99.2 & 38.3 & 1 \\
\hline & & & Control & 19.15 & 36.3 & 0.001 \\
\hline
\end{tabular}

ung

interpret the conduct of children, their own behaviors, occurrences, and relationships.

The protocol enables parents to have a precise and thorough self-report on their behaviors [19]. Triple P teaches parents how to encourage positive habits of children and in turn, children's positive activities have beneficial impacts on the emotions and behaviors of parents through a positive cycle [20]. One meta-analysis undertaken by Nowak and Heinrich found that Triple $P$ has a potent efficacy in enhancing parents' and children's behavior [17]. Triple P can generally improve understanding and abilities, train problem-solving skills, expand entertainment and safety, and increase cognitive, mental, verbal, emotional and social skills in mothers [19].

With regard to the efficacy of ACT-based parenting, our findings supported the efficacy of ACT on the parent-child relationship and parental self-efficacy in mothers with ODD children. The positive results of
ACT continued up to the follow-up stage. This result was consistent with some other research studies [28-30]. In research on the efficacy of ACT-based parenting in families with children with a deadly disease, Burke et al. found that ACT could decrease psychological issues and enhance the abilities of parents. Their findings showed that this improvement continued even 6 months after the study completion [25]. Azimifar et al. found that ACTbased parenting could enhance the parental self-efficacy of mothers with children who have externalizing behavioral problems [29].

It should be noted that the ACT's most significant objective is the absence of experiential avoidance and increased psychological flexibility [24]. Children's mothers with ODD seem to avoid interactions with their children, and this scenario often leads to punitive, inflexible, and incoordinate techniques adopted by parents $[7$, 11]. ACT-based parenting teaches these mothers not to escape but attempt to embrace such situations, leading 
them to avoid misbehaviors and to be flexible in reaction to their condition.

ACT also emphasizes active action [24], so parents learn to embrace a healthy parenting strategy using the education they receive and not give up and restrain their parenting conduct if the child harasses them. One of ACT-based parenting's primary objectives is to concentrate on the subjective evaluation of child behaviors by the parents. ACT helps parents monitor their cognitive, behavioral, and emotional needs and manage them. Children sometimes create behavioral issues and ask their parents to fulfill their desires, but real parenting is that parents should embrace these behaviors and not give up the kid instantly. The ACT teaches parents how to respond to these behaviors. In reality, ACT enables parents to learn behavioral management [29], leading to enhanced child interactions, and therefore a sense of parental self-efficacy.

Furthermore, the findings of this research showed no significant difference between the parent-child relationship efficacy of Triple P and ACT-based parenting and parental self-efficacy that continued up to the follow-up stage. This demonstrates that both instructional programs could significantly impact mothers with kids suffering from ODD by providing expertise and abilities. According to the outcomes, it is not possible to prefer one instructional program over the other. Recently, the researchers have tried to incorporate these two training protocols. Brown et al., in two independent research studies showed that the combination of Triple $\mathrm{P}$ and ACT-based parenting could lead to a notable enhancement and a major impact on parents and kids [27, 40]. It is therefore suggested that scientists attempt to incorporate these two instructional methods and examine the effect of the combined protocol on parents and children. This research suffered from certain limitations, like other studies. Caution must be taken in generalizing the findings as study variables have been assessed using the questionnaires that is predisposed to biased responses. Due to time limitations, the research also lacked a more extended follow-up period (e.g. 6 months).

\section{Conclusion}

Parenting based on Triple P and ACT enhance parentchild relationships and self-efficacy of mothers with children with ODD. It is therefore proposed that specialists attempt to use both instructional programs for parents. It is expected that more and better services be provided for parents through the implementation of studies and the integration of these two programs.

\section{Ethical Considerations}

\section{Compliance with ethical guidelines}

Hormozgan University of Medical Sciences approved this study (the Ethical Code: IR.HUMS.REC.1398.126).

Funding

This paper was extracted from a $\mathrm{PhD}$. thesis of the firstauthor at Hormozgan University.

\section{Authors' contributions}

Conceptualization, manuscript drafting: All authors; Data collection and analysis: Shahriar Amini Naghani.

\section{Conflict of interest}

The authors declared no conflict of interest.

\section{References}

[1] American Psychiatric Association. Diagnostic and statistical manual of mental disorders (DSM-5®). Washington, DC: Am Psychiatric Pub; 2013. [DOI:10.1176/appi. books.9780890425596]

[2] Ezpeleta L, Navarro JB, de la Osa N, Penelo E, Domènech JM. First incidence, age of onset outcomes and risk factors of onset of DSM-5 oppositional defiant disorder: A cohort study of Spanish children from ages 3 to 9. BMJ open. 2019; 9(3):e022493. [DOI:10.1136/bmjopen-2018-022493] [PMID] [PMCID]

[3] Rezabaygi Davarani M. [A glance over the confrontational disorder, conduct disorder and anti-social behavior (Persian)]. Exceptional Education. 2013; 1(114):58-67.

[4] Burke JD, Rowe R, Boylan K. Functional outcomes of child and adolescent oppositional defiant disorder symptoms in young adult men. J Child Psychol Psychiatry. 2014; 55(3):26472. [DOI:10.1111/jcpp.12150] [PMID] [PMCID]

[5] Burke JD, Hipwell AE, Loeber R. Dimensions of oppositional defiant disorder as predictors of depression and conduct disorder in preadolescent girls. J Am Acad Child Adolesc Psychiatry. 2010; 49(5):484-92. [DOI:10.1016/j.jaac.2010.01.016]

[6] Burke J, Loeber R. Oppositional defiant disorder and the explanation of the comorbidity between behavioral disorders and depression. Clin Psychol: Sci Pract. 2010; 17(4):319-26. [DOI:10.1111/j.1468-2850.2010.01223.x]

[7] Jalali M, Shaeeri M, Tahmasian K, Pourahmadi E. [The effects of triple P-Positive Parenting Program on 7-10 Year old Children with Oppositional Defiant Disorder (ODD) (Persian)]. Clin Psychol Pers. 2009; 1 (34):29-38. 
[8] Costin J, Chambers SM. Parent management training as a treatment for children with oppositional defiant disorder referred to a mental health. Clin Child Psychol Psychiatry. 2007; 12(4):511-24. [DOI:10.1177/1359104507080979] [PMID]

[9] Zisser A, Eyberg SM. (2010). Parent-child interaction therapy and the treatment of disruptive behavior disorders. In Weisz JR \& Kazdin AE, editors. Evidence-based Psychotherapies for Children and Adolescents. New York: The Guilford Press; 2010.

[10] Burke JD, Romano-Verthelyi AM. Oppositional defiant disorder. In: Martel MM. Developmental Pathways to Disruptive, Impulse-Control and Conduct Disorders. Cambridge: Academic Press; 2018. [DOI:10.1016/B978-0-12811323-3.00002-X]

[11] Roskam I, Brassart E, Loop L, Mouton B, Schelstraete MA. Stimulating parents' self-efficacy beliefs or verbal responsiveness: Which is the best way to decrease children's externalizing behaviors? Behav Res Ther. 2015; 72:38-48, [DOI:10.1016/j.brat.2015.06.012] [PMID]

[12] Jones TL, Prinz RJ. Potential roles of parental self-efficacy in parent and child adjustment: A review. Clin Psychol Rev. 2005; 25(3):341-63. [DOI:10.1016/j.cpr.2004.12.004] [PMID] [PMCID]

[13] De Montigny F, Lacharité C. Perceived parental efficacy: Concept analysis. J Adv Nurs. 2005; 49(4):387-96 [DOI:10.1111/j.1365-2648.2004.03302.x] [PMID]

[14] Ardelt M, Eccles JS. Effects of mothers' parental efficacy beliefs and promotive parenting strategies on inner-city youth J Fam Issues. 2001; 22(8):944-72. [DOI:10.1177/01925130102 2008001]

[15] Dretzke J, Frew E, Davenport C, Barlow J, Stewart-Brown $\mathrm{S}$, Sandercock J, et al. The effectiveness and cost-effectiveness of parent training/education programmes for the treatment of conduct disorder, including oppositional defiant disorder in children. Health Technol Assess. 2005; 9(50):iii, ix-x, 1-233. [DOI:10.3310/hta9500] [PMID]

[16] Sanders MR, Baker S, Turner KM. A randomized controlled trial evaluating the efficacy of Triple P Online with parents of children with early-onset conduct problems. Behav Res Ther 2012; 50(11):675-84. [DOI:10.1016/j.brat.2012.07.004] [PMID]

[17] Nowak C, Heinrichs N. A comprehensive meta-analysis of Triple P-Positive Parenting Program using hierarchical linear modeling: Effectiveness and moderating variables. Clin Child Fam Psychol Rev. 2008; 11(3):114-44. [DOI:10.1007/s10567008-0033-0] [PMID]

[18] Sanders MR. Triple P-Positive Parenting Program: A population approach to promoting competent parenting. AeJAMH. 2003; 2(3):127-43. [DOI:10.5172/jamh.2.3.127]

[19] Arjmandnia AA, Ashoori M, Jalil Abkenar S. [Comprehensive view to positive parenting program: Principle, goals, levels and content (Persian)]. Frooyesh. 2017; 6(2): 35-52.

[20] Pickering JA, Sanders MR. Reducing child maltreatment by making parenting programs available to all parents: A case example using the Triple P-Positive Parenting Program. Trauma Violence Abuse. 2016; 17(4):398-407. [DOI:10.1177/1524838016658876] [PMID]

[21] Sanders MR, Kirby JN, Tellegen CL, Day JJ. The triple P-Positive Parenting Program: A systematic review and meta-analysis of a multi-level system of parenting support. Clin Psychol Rev. 2014; 34(4):337-57. [DOI:10.1016/j. cpr.2014.04.003] [PMID]

[22] Talei A, Tahmasian K, Vafaie N. [Effectiveness of positive parenting program training on mothers' parental self-efficacy (Persian)]. Family Research. 2011; 7(3): 311-323.

[23] Momeni Kh M, Taziki T. [The effectiveness of positive parenting program on parent-child communication and parental stress among students with attention deficit (Persian)]. Empowering Except Child. 2018; 8(1): 83-93.

[24] Hayes SC, Strosahl KD, Wilson KG. Acceptance and commitment therapy. Washington, D.C: American Psychological Association; 2009.

[25] Burke K, Muscara F, McCarthy M, Dimovski A, Hearps $\mathrm{S}$, Anderson V, et al. Adapting acceptance and commitment therapy for parents of children with life-threatening illness: Pilot study. Fam Syst Health. 2014; 32(1):122. [DOI:10.1037/ fsh0000012] [PMID]

[26] Whittingham K, Sanders MR, McKinlay L, Boyd RN. Parenting intervention combined with Acceptance and Commitment Therapy: A trial with families of children with cerebral palsy. J Pediatr Psychol. 2015; 41(5):531-42. [DOI:10.1093/ jpepsy/jsv118] [PMID] [PMCID]

[27] Brown FL, Whittingham K, Boyd RN, McKinlay L, Sofronoff $\mathrm{K}$. Does stepping stones triple $\mathrm{P}$ plus acceptance and commitment therapy improve parent, couple, and family adjustment following paediatric acquired brain injury? A randomized controlled trial. Behav Res Ther. 2015; 73:58-66. [DOI:10.1016/j.brat.2015.07.001] [PMID]

[28] Blackledge JT, Hayes SC. Using acceptance and commitment training in the support of parents of children diagnosed with autism. Child Fam Behav Ther. 2006; 28(1):1-8 [DOI:10.1300/J019v28n01_01]

[29] Azimifar Sh, Jazayeri R, Fatehizade M, Abedi A. [Evaluating the effect of parent training based on an acceptance and commitment therapy on parenting self-efficacy in mothers of children with externalizing behavior problems (Persian)]. Fam Res. 2018; 14(3): 443-57.

[30] Gould ER, Tarbox J, Coyne L. Evaluating the effects of acceptance and commitment training on the overt behavior of parents of children with autism. J Contextual Behav Sci. 2018; 7:81-8. [DOI:10.1016/j.jcbs.2017.06.003]

[31] Delavar A. [Theoretical and practical foundations of research in the humanities and social sciences (Persian)]. Tehran: Roshd Publication; 2015.

[32] Briesmeister JM, Schaefer CE. Handbook of parent training: Helping parents prevent and solve problem behaviors Hoboken: John Wiley \& Sons; 2007.

[33] Coyne L, Murrell A. The joy of parenting: An acceptance and commitment therapy guide to effective parenting in the early years. Oakland: New Harbinger Publications; 2009.

[34] Hommersen P, Murray C, Ohan JL, Johnston C. Oppositional defiant disorder rating scale: Preliminary evidence of reliability and validity. J Emot Behav Disord. 2006; 14(2):118 25. [DOI:10.1177/10634266060140020201] 
[35] Faramarzi S, Abedi A, Ghanbari A. [Mother communication patterns and oppositional defiant disorder of children (Persian)]. Med J Tabriz Univ Med Sci. 2012: 34(2):90-6.

[36] Pianta RC. Child-parent relationship scale. Unpublished measure, University of Virginia. 1992; 427. https://www. bristol.ac.uk/media-library/sites/sps/documents/cchange/cprs.pdf

[37] Abarashi Z, Tahmasian K, Mazaheri MA, Panaghi L. [The impact of psychosocial child development training program, done through improvement of mother-child interaction, on parental self-efficacy and relationship between mother and child under three (Persian)]. J Res Psychol Health. 2009; 3(3):49-57.

[38] Dumka LE, Stoerzinger HD, Jackson KM, Roosa MW. Examination of the cross-cultural and cross-language equivalence of the parenting self-agency measure. Fam Relat. 1996; 45(2):216-22. [DOI:10.2307/585293]

[39] Bodenmann G, Cina A, Ledermann T, Sanders MR. The efficacy of the triple P-Positive Parenting Program in improving parenting and child behavior: A comparison with two other treatment conditions. Behav Res Ther. 2008; 46(4):41127. [DOI:10.1016/j.brat.2008.01.001] [PMID]

[40] Brown FL, Whittingham K, Boyd RN, McKinlay L, Sofronoff $\mathrm{K}$. Improving child and parenting outcomes following paediatric acquired brain injury: A randomized controlled trial of stepping stones triple P plus acceptance and commitment therapy. J Child Psychol Psychiatry. 2014; 55(10):117283. [DOI:10.1111/jcpp.12227] [PMID] 
This Page Intentionally Left Blank 